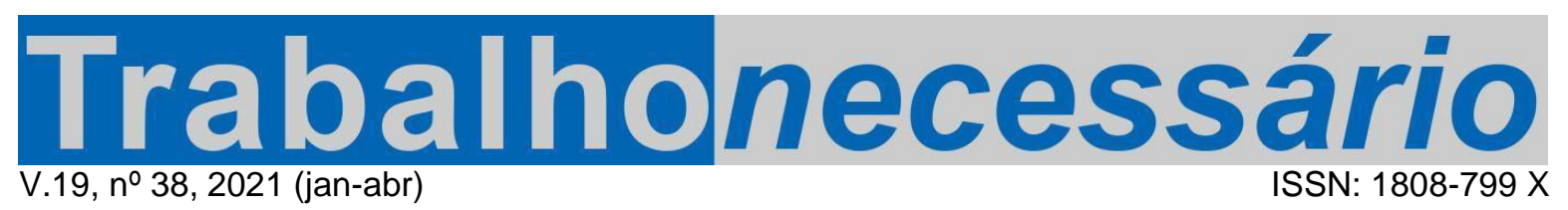

\title{
DESENGAVETANDO GÊNERO À LUZ DOS FEMINISMOS NO BRASIL ${ }^{1}$
}

\author{
Tatiana Dahmer Pereira²
}

\begin{abstract}
Resumo
$\mathrm{O}$ artigo trata de questões emanadas pela diversidade de resistências de movimentos de diferentes mulheres no Brasil, as quais se norteiam por vivências concretas distintas e com projetos societários variados. De caráter teórico - porém fundado em trajetória pessoal e profissional da autora junto aos movimentos feministas e de mulheres - visa refletir sobre as diferentes visibilidades e mesmo invisibilizações de movimentos de mulheres e feministas, a partir da dinâmica particular de nossa formação social brasileira. Ao final, visando futuros do debate, sinalizamos elementos importantes para os estudos de feminismos, movimentos de mulheres e de gênero na academia.
\end{abstract}

Palavras-chave: Gênero. Relações sociais de sexo. Raça. Classe social. Formação social brasileira.

\section{DESHACIENDO GÉNERO A LA LUZ DE LOS FEMINISMOS EN BRASIL}

\section{Resumen}

El artículo trata temas derivados de la diversidad de resistencias de movimientos de diferentes mujeres en Brasil, que se basan en diferentes experiencias concretas y con variados proyectos sociales. De carácter teórico -pero fundada en la trayectoria personal y profesional de la autora con los movimientos feministas y de mujeres- pretende reflexionar sobre las diferentes visibilidades e incluso invisibilidades de los movimientos de mujeres y feministas, desde la particular dinámica de nuestra formación social brasileña. Al final, con el objetivo de futuros del debate, señalamos elementos importantes para los estudios de feminismos, movimientos de mujeres y género en la academia.

Palabras clave: Género. Relaciones sociales. Raza. Clase social. Formación social brasileña.

\section{UNDRAWERING GENDER IN THE LIGHT OF FEMINISMS IN BRAZIL}

\author{
Abstract \\ The article deals with issues emanating from the diversity of resistances of movements of different \\ women in Brazil, which are based on different concrete experiences and with varied societal projects. \\ Of theoretical character - but founded on the author's personal and professional trajectory with feminist \\ and women's movements - aims to reflect on the different visibilities and even invisibilities of women's \\ and feminist movements, from the particular dynamics of our Brazilian social formation. In the end, \\ aiming at futures of the debate, we signaled important elements for the studies of feminisms, women's \\ movements and gender in university. \\ Keywords: Gender. Social and sex relations. Race. Social class. Brazilian social formation. \\ 1 Artigo recebido em 14/01/2021. Primeira avaliação em 18/01/2021. Segunda avaliação em \\ 22/01/2021. Aprovado em 05/02/2021. Publicado em 25/02/2021. \\ DOI: https://doi.org/10.22409/tn.v19i38.48161 \\ 2 Doutora em Planejamento Urbano e Regional (IPPUR-UFRJ), docente e pesquisadora do \\ PPGSSDR- \\ UFF, formada em Serviço Social (UFRJ). Pesquisadora apoiada pelo CNPq. \\ E-mail: tatianadahmerpereira@gmail.com Lattes: http://lattes.cnpq.br/2619212275317172 \\ ORCID: https://orcid.org/0000-0002-1096-8950
}




\section{Introdução}

A presente reflexão ${ }^{3}$ foca em questões geradas pelas formas de resistências engendradas por movimentos históricos de diferentes mulheres, com suas especificidades, as quais se norteiam por vivências concretas distintas e, necessariamente, possuem projetos societários diversos. Procuramos dialogar, aqui, com os desdobramentos dessas questões no campo dos feminismos e mesmo nos rebatimentos dessas construções no âmbito de espaços de produção de conhecimento. Consideramos essa abordagem importante, na medida em que nos auxilia a compreender as mobilizações das trajetórias de movimentos (feministas e de mulheres) no Brasil e suas relações/conexões em torno do conceito de gênero na contemporaneidade.

A questão que nos norteia é como essa diversidade se constrói no contexto da modernidade periférica ${ }^{4}$ e qual a sua relação com os dilemas existentes entre tais formas de resistência, seus registros e reconhecimentos nos movimentos sociais e espaços de produção de conhecimento.

Considerando os limites do espaço de um artigo, realizamos breve historicidade visando problematizar os seguintes elementos: (i) diferentes visibilidades e mesmo invisibilizações e silenciamentos sociais e políticas de movimentos de mulheres de corte feminista, a partir da dinâmica particular de nossa formação social brasileira; (ii) diálogos, confrontos e (re)significações do conceito de gênero com base nessas formas de resistência; (iii) interconexões e conflitos com as formas de organizações e de resistência do que se nomeia como campo histórico da diversidade (de identidade de gênero e sexual).

\footnotetext{
${ }^{3} \mathrm{O}$ texto é uma reflexão fundada em experiências/vivências junto a movimentos feministas, de diversidade e de mulheres desde os anos de 1990, assim como da trajetória de estudos e trabalho profissional tanto no campo de assessoria e formação política junto a movimentos sociais quanto da docência no ensino superior A partir de ingresso como docente na universidade, em 2009, deparo-me com os esforços de ministrar disciplina para discentes de graduação sobre relações de gênero, gerando, então, reflexões permanentes sobre essas relações entre a produção acadêmica e o cotidiano das produções de conhecimento a partir de movimentos sociais.

4 Por modernidade periférica compreendemos as relações constituídas de subjugação pela dependência da dinâmica dos países centrais quanto à exportação e demais relações geopolíticas, que imprimem particularidades distintas ao processo modernizador brasileiro. Alguns autores trazem contribuições distintas e importantes quanto à constituição desses elos (MENEGAT, 2019; COUTINHO, 2000 e OLIVEIRA, 2003 são os centrais em nossa leitura).
} 
Os três pontos mencionados anteriormente consistem no caminho traçado no artigo. Ao final, a título de desdobramentos futuros do debate, sinalizamos elementos importantes para os estudos de gênero na academia.

\section{Questões iniciais sobre essa forma social e sua materialidade na periferia do capitalismo}

Um primeiro ponto trazido por nós refere-se aos contextos e processos históricos nos quais se constroem os reconhecimentos e visibilidades no Brasil quanto às formas de resistência e lutas de movimentos de mulheres e feministas. Essa análise, merecedora de maior elaboração e adensamento, se restringirá aqui a alguns elementos centrais em função dos limites do espaço. Porém, consideramos sua relevância na medida em que expressa muito das formas estruturantes da sociabilidade brasileira, não sendo possível pensá-los sem entender a formação do mundo moderno e suas particularidades.

Consideramos como marcos da fundação da modernidade processos os quais viabilizam a generalização das relações mercantis e a racional separação entre ser humano e natureza. A substância desta forma social conforma-se, como discutimos em trabalhos pregressos ${ }^{5}$, na conflagração processual da centralidade de um tipo particular de ser humano difundido e legitimado como universal: o homem branco (caucasiano), europeu, possessivo/proprietário e heteronormativo. Esta afirmação se constrói a partir das expansões europeias ultramarinas iniciadas no século XV, mas assenta-se sobre forçosos adventos profundamente violentos - paradoxalmente como forma de construção positiva da identidade do "homem" da modernidade.

Citamos aqui alguns aspectos centrais para a nossa argumentação:

(i) as inquisições da Igreja Católica como imposição de poder e ordenamento do que era a forma "estatal", refuncionalizando violentamente o lugar social e os corpos das mulheres (FEDERICI, 2017), conflagrando o que Segato (2016) nomeia como uma "guerra contra as mulheres";

(ii) as objetificações (reificações) do real, com as separações e hierarquizações entre o campo e a cidade, o político e o econômico, entre outras dualidades construídas na

5 (PEREIRA, 2019; PEREIRA et al 2019). 
era moderna. Wood (2000) demonstra como as raízes agrárias do capitalismo instituem marcos fundadores da propriedade privada e da despossessão na Inglaterra, por exemplo;

(iii) a ressignificação do lugar do trabalho e, conseqüentemente, da construção de uma moral positivada com as reformas protestantes (século XVI);

(iv) o colonialismo escravista, em especial, na violenta dominação territorial e subjugação de povos originários não reconhecidos em sua humanidade; como central para a "acumulação primitiva" e a configuração de relações de desenvolvimento dependente e subordinado e, por fim, mas não menos relevante;

(v) os avanços das ciências e a otimização (e imposição) do tempo e do ordenamento do espaço na construção da vida cotidiana a partir da consolidação da razão iluminista, imposta como universal.

Esses ingredientes fundam e alimentam de forma não linear e marcada por muitas contradições geradas pelos embates cotidianos de afirmação em torno de quem é passível do reconhecimento de humanidade. Configuram-se de forma distinta em função das formações sociais de cada lugar e das relações geopolíticas o que hoje estruturam as ações do Estado capitalista. Porém, para nós algo as unifica, considerando a dinâmica impressa às relações, o que Gonçalves (2019) explicita como a forma específica e única à modernidade: o patriarcado produtor de mercadorias. Este possui por centralidade a valorização do valor como um fim em si mesmo e a difícil compreensão dos sujeitos sobre a objetividade por eles produzida (GONÇALVES, 2019, pp.41-42).

Essa dinâmica fetichista estrutura-se sobre a dinâmica das relações sociais, com as desigualdades entre as classes sociais, os tensionamentos do patriarcado moderno 6 e o racismo estrutural. Este último se expressa através da hierarquização e da desumanização permanentes nas diferenças racializadas entre os seres humanos na vida social. Um dos sinais é a banalização em torno de quais vidas podem se perder ou consistem em ameaça social. Recuperamos o quanto esses elementos conflagram

\footnotetext{
${ }^{6}$ Reforçamos, como algo distinto das outras estruturas patriarcais e com formas próprias de controle dos corpos das mulheres, na sua desumanização e objetificação, das definições identitárias de gênero e na afirmação permanente da divisão sexual do trabalho (GONÇALVES, 2019).
} 
o que Fanon (2008) nomeia criticamente como a construção histórica da "outridade"7 e que Segato (2007) problematiza como a antítese da construção da ideia homogeneizadora de nação: os outros.

Nessa ótica, a narrativa histórica hegemônica que consolida a ideia do feminismo em "ondas" por anos invisibilizou ou desqualificou formas de resistência e de luta pela vida, contra opressões e pela liberdade - na materialidade perigosa de uma história única (ADICHIE, 2019). Essa mesma leitura muitas vezes trabalha com uma ideia de movimento feminista (e não de movimentos feministas e movimentos de mulheres), e alinha essa qualificação cronológica ${ }^{8}$ da construção das lutas à conformação dos direitos de cidadania dentro de uma perspectiva bastante marshalliana ${ }^{9}$.

Ao construir a consciência universal e racional, o faz incidindo sobre 0 apagamento de memórias e histórias diversas (GONZALES, 1984). Por exemplo, quando do reconhecimento de formas de resistências permanentes à escravização, os quilombos foram, por muito tempo, mencionados como lugares de fuga, em uma clara animalização e subalternização das pessoas africanas - e não compreendidos nas suas riquezas e complexidades, como estratégias e espaços de sociabilidade de resistência cultural, afetiva e de organização dos enfrentamentos que contribuíram

\footnotetext{
7 Para Fanon (2008) o conceito de outridade se constitui para designar o negro como o outro em relação ao branco em uma distinção negativa, de tudo aquilo que o branco não reconhece em si. Em leitura crítica com base na psicanálise, repensa a alteridade como um elemento próprio à construção da identidade do indivíduo a partir da conformação dessas distinções e hierarquias sociais.

8 Nosso desconforto com a narrativa histórica de um movimento feminista universal que pode ser narrado a partir de "ondas" traz simplificações bastante delicadas no que tange ao reconhecimento político e histórico da diversidade dos feminismos e movimentos de mulheres. Por exemplo, ao se assinalar a primeira onda do feminismo como marcado pelas lutas das sufragistas pelos direitos ao voto (e pela cidadania na sua dimensão política), ignoram-se outras formas históricas anteriores de insurgência e resistência das mulheres, como no caso das mulheres escravizadas nas Américas, por exemplo. Estas não necessariamente tematizavam ou qualificavam suas lutas como direitos políticos, mas na concretude essas formas de resistência pelo direito a existir dignamente, sem sofrer violações de seus corpos, materializa-se como movimento coletivo de resistência, ainda que não se nomeie nem se reconheça como feminista. Algo bastante semelhante ocorre com a "segunda onda", narrada como momento de pleito ao direito ao ingresso no mercado de trabalho, ao controle sobre seus corpos e vivência enquanto mulheres. Essa não era, necessariamente, a pauta central das mulheres negras, por exemplo, tanto no Brasil quanto em outros países ocidentais, na medida em que o trabalho e sua dimensão opressiva e exploratória sempre se fizeram presentes na vida das mulheres negras - mas são muitas vezes sistematicamente silenciados sendo necessário "enegrecer o feminismo" (CARNEIRO, 2003).

9 Referenciamos a leitura de T. H. Marshall (1967) sobre cidadania, em contexto de pós-guerra e expansão capitalista - na qual o autor defende a possibilidade de compatibilidade entre desigualdade e direitos. O autor desenvolve a recuperação cronológica e etapista das dimensões que ele credita à conformação da construção da cidadania.
} 
para corroer por dentro as estruturas da escravidão no Brasil. Mais ainda, a invisibilidade das mulheres africanas e afro-descendentes nas lutas de resistência à escravidão é algo permanente, ganhando alguma projeção e visibilidade dos registros graças aos resgates históricos, reconstrução de histórias orais e às pesquisas e registros acadêmicos realizados por aquelas que têm sido sujeitos da visibilização e do resgate de outras narrativas históricas em torno dessas lutas, em especial a partir dos anos de 1970 (GONZALES, 1984; CARNEIRO, 2003; LUGONES, 2008 como alguns exemplos).

\section{Movimentos de mulheres e movimentos feministas - conexões, distinções e contradições}

É a partir da conformação histórica moderna, com suas contradições e violências intrínsecas, que reforçamos a importância do reconhecimento das formas de opressão desde a sua origem. Essas formas se naturalizam na espoliação cotidiana e assumem características cada vez mais complexas. Por isso, o resgate da história e da memória tanto das opressões e violações quanto, especialmente, das formas de resistência e dos embates produzidos por elas, são recursos políticos e epistêmicos fundamentais de visibilidade, reconhecimento, registro e de fortalecimento das diferentes existências e construções do feminino no Brasil na contemporaneidade.

Uma observação inicial é importante na organização dessa argumentação: embora as formas de resistência das mais diferentes mulheres às distintas opressões históricas sempre tenham existido, ainda que invisibilizadas, as narrativas sobre as mesmas e a nomeação dada a estas de "feminismo" é algo bastante controverso e polêmico. Por isso também reforçamos a distinção entre movimentos de mulheres e feminismos.

A delicada questão é que a narrativa hegemônica quanto ao que seria uma história do feminismo no Brasil (PINTO, 2003 e 2010; TELES, 1999) nos apresenta registros importantes, porém extremamente parciais e marcados pela exposição da condição das mulheres como mulher universal. Essa questão é central para se compreender as armadilhas de não ruptura com essa forma social do patriarcado produtor de mercadorias, como mencionamos, e que alimentam opressões e desigualdades internas dos próprios movimentos de mulheres e de movimentos feministas em nossa história. Não se trata apenas de um reconhecimento formal, 
de alteração de nomenclaturas ${ }^{10}$, mas da centralidade do resgate e reconhecimento dessa diversidade, das contradições existentes e das demandas específicas das diferentes mulheres em seu existir a partir dos marcadores fundamentais como raça, classe social e mesmo caminhos da construção identitária de gênero ${ }^{11}$.

Os limites concretos e políticos dessa leitura universalizante situam-se justamente na construção de pautas únicas e na hierarquização de demandas e lutas de diferentes mulheres. Por exemplo, tanto a predominância da visibilidade dos feminismos liberais quanto até mesmo de uma leitura clássica de feminismos marxistas, em geral priorizam uma dada construção de igualdade das mulheres em relação aos homens e a partir de uma premissa de mulher universal - alimentando e mantendo esta ideação do que é o parâmetro a se conquistar. A interessante crítica de Roswitha Scholz (1996) problematiza essa construção feita a partir da centralidade da dinâmica do valor, que em nada contribui para a ruptura com o fato que o "valor é o homem".

Em argumentação por caminhos distintos, Fraser (2019) pondera sobre os limites da "segunda onda" do feminismo, no pós II guerra mundial - chamando a atenção para o fato que "o sucesso relativo do feminismo na transformação da cultura contrasta nitidamente com seu relativo fracasso na transformação das instituições" (p.26). A autora problematiza a abordagem dualista e simplista segundo a qual existiria uma falha institucional com sucesso cultural, na medida em que essas mudanças não impactaram as instituições. Sinaliza como uma de suas causas as próprias transformações na organização social do capitalismo e considera que "o verdadeiramente novo na segunda onda foi o entrelaçamento, na crítica ao

10 Gonzales (1984) problematizava a relevância de recuperar e construir autonomeações ou autodefinições, narrativas e "epistemes" próprias, não eurocêntricas. Nos Estados Unidos da América, Collins (2019) problematiza a adoção eurocêntrica da nomeação "feminismo", propondo a construção de nomeação própria aos movimentos das mulheres negras, "mulherismo" (womanism).

11 Reforçamos aqui o elemento da construção identitária, na medida em que ele é central na modernidade. No entanto, a identidade do indivíduo aparece como uma abstração que se materializa em uma forma única e universal, como no caso da "mulher". O ser mulher como uma construção social a partir das suas mais diferentes vivências, das contradições estruturais e dos caminhos de construção dessa identidade se configura com diferentes compreensões no seio dos feminismos, redefinindo campos próprios, como o transfeminismo, ao se considerar "o ponto em que o transfeminismo diz respeito às vidas das pessoas transexuais, travestis e transgêneras" de forma a visibilizar e não apagar a existência de pessoas trans na sociedade (BAGAGLI, 2018, p.345). Nessa mesma publicação, Vieira (2018) afirma que "ora, se a própria noção de sexo pode ser compreendida histórica e situacionalmente, então as 'causalidades compulsórias' vagina-mulher-feminilidade/homem-pênis-masculinidade se desestabilizam, e começamos a pensar, portanto, nos corpos que escapam dessas tríades, os corpos transexuais e travestis" (p.357). 
capitalismo androcêntrico organizado pelo Estado ${ }^{12}$, de três dimensões analiticamente distintas de injustiça de gênero: a economia, a cultural e a política" (FRASER, 2019, p.32).

Esse aporte, para os quais os feminismos hegemônicos universalizantes acabam por convergir, faz com que os registros das histórias dos feminismos sejam marcados como tendo o passo inicial os movimentos sufragistas a partir da segunda metade do século XIX com maior projeção no início do XX e a luta das mulheres brancas pela inserção no mercado de trabalho. Isso não apenas não é um consenso, como não enfrenta as questões trazidas pelas mulheres negras e indígenas, por exemplo, quanto à prioridade no reconhecimento de sua humanidade, na denúncia da histórica violação e erotização de seus corpos, na desapropriação de suas terras e apartação dos recursos naturais e saberes ancestrais e do não reconhecimento quanto à histórica integração subalternizada e violenta ao trabalho (seja forçado, escravizado ou "livre").

Embora a leitura hegemônica possua preponderância, a presença e posicionamento de registros das leituras contra-hegemônicas se fazem presentes há tempos, adquirindo maior força, impulso e, especialmente, visibilidade a partir dos anos de 1970 no Brasil com as contribuições de autoras fundamentais como Gonzales (1984) e Carneiro (2003), entre outras.

Soma-se ao aprofundamento das distinções raciais e de classe social entre mulheres, avanços dos debates identitários não essencialistas sobre ser mulher e caminhos distintos que enfrentam, no campo da diversidade sexual, a imposição histórica patriarcal da heteronormatividade. Essa riqueza de reflexões não ocorre, obviamente, de forma tranqüila por dentro dos movimentos - o que é importante para mexer com as estruturas (CARNEIRO, 2003). A autora sintetiza bem essa questão ao demonstrar o quanto

a origem branca do feminismo estabeleceu sua hegemonia na equação das diferenças de gênero e tem determinado que as mulheres não brancas e pobres, de todas as partes do mundo, lutem para integrar em seu ideário as especificidades raciais, étnicas, culturais,

\footnotetext{
${ }^{12}$ Realiza essa reflexão com base em Friedrich Pollock e referenciada nas experiências de Estado de Bem Estar Social (p.28), uma realidade bem distinta da nossa trajetória de formação no Brasil e mesmo latino-americana.
} 
religiosas e de classe social. Até onde as mulheres brancas avançaram nessas questões? (CARNEIRO, 2003, p.318)

Distintos registros em torno de formas e movimentos de resistências e enfrentamentos de opressões e violências por parte das diferentes mulheres na história e nos lugares podem ser mapeados a partir das distintas reflexões críticas e deste embate travado por dentro dos feminismos, impulsionados pelas mulheres negras, pelas mulheres trans e mesmo as indígenas. Se demandas, denúncias, tensões emanadas dos movimentos do real rebatem nas universidades como temas e, necessariamente, metodologias analíticas e campos teóricos nos anos de 1960 na Europa e América do Norte e nos de 1970 na América Latina ${ }^{13}$, a tentativa de identificar, classificar, analisar, compreender o real como elementos constitutivos do saber acadêmico hegemonicamente iluminista tem sido sistematicamente questionada, vivenciando impactos e desafios importantes que desequilibram uma estrutura aparentemente asséptica de produção do saber "formal".

Essa não é uma questão periférica ou menor, na medida em que as possibilidades geradas pela força política das abordagens dos feminismos negros e movimentos mulheristas (COLLINS, 2019) e ligados também à diversidade de gênero e sexual e daqueles vinculados aos deslocamentos em relação ao eurocentrismo, como a proposta de feminismos decoloniais críticos, demarcam não apenas espaços nem tampouco se propõem a pactuar agregação de temas e enfoques. Incidem sobre clara disputa por inscrever histórias e recontar outras a partir das perspectivas de distintas vivências dos femininos e existências de mulheres, de outras perspectivas, de deslocar o foco e a luz sobre quem são narradoras e produtoras de interpretações - e como o saber hegemônico pouco tem historicamente contribuído para visibilidade, enfrentamento de opressões estruturais, compreensões da diversidade e da complexidade do mundo.

A grande questão, ao se considerar tempos atuais, de aprofundamento da crise capitalista no final do século XX acompanhado do recrudescimento de formas totalitárias e fundamentalistas expressas na sociedade e materializadas em ações

\footnotetext{
${ }^{13}$ Essa cronologia não é muito precisa, mas sinaliza para o tardio reconhecimento de movimentos importantes do real, como os trazidos pelos feminismos e lutas antirracistas e anti colonialistas inicialmente incorporados de forma periférica e, muitas vezes, tratados pelo mainstream na academia como temas coadjuvantes ou de baixa qualificação teórica.
} 
estatais - as quais impactam diretamente e de modos distintos as mulheres -, é pensar como, se e qual tipo de saber feminista e do campo dos estudos de gênero possui papel relevante. Para nós, essa relevância se faz presente quando este saber é constituído a partir de perspectiva desestabilizadora e consistente das estruturas que tradicionalmente valorizam determinadas epistemes formais, que mais servem para alimentar novas hierarquias e opressões sem incidir em instrumentos capazes de contribuir para a compreensão (ainda que parcial) de movimentos do real.

Sem receitas ou formatos prévios, o que desestabiliza certezas e definições geralmente tem se fundado em trajetórias periféricas, marginalizadas, coletivas, colaborativas, de valorização de relações originárias e um passado resgatado a contrapelo (pelas bases da ancestralidade, na contraposição a uma ideia de história única e universal, conforme defende ADICHIE, 2019), da construção dos "comuns" (FEDERICI, 2019) e com base em práticas afetivas e metodologias pedagógicas agregadoras na diversidade.

Essas vivenciam múltiplas compreensões em construção sobre os lugares e usos do saber - com todas as contradições possíveis ao fazê-lo nesse mundo, sob essa forma social. Ainda assim, contribuem não apenas para aprendizados novos e a apreensão conceitual de conteúdos, mas sua contextualização histórica a partir do reconhecimento das vivências na História, de percepção de contradições, violências, opressões e crise como elementos motores da constituição moderna.

Nesse sentido, o saber não deve contribuir para edificar doutrinas ou trazer certezas impermeáveis, nem deve nos colocar em pedestais ou criar distinções hierárquicas, ao mesmo tempo que nos perguntamos: como reconstruir abordagens, leituras e compreensões sem esvaziar seus conteúdos originários a partir de experiências vividas?

Tampouco deve nos trazer alívio nas certezas doutrinárias - este é o papel, quando muito, das religiões -, mas sim nos desafiar acolhedoramente à compreensão do que nos parece tão difícil, distante e alheio a nós. Deve, especialmente, nos ajudar a romper nossa preocupação central de definição de sujeitos conhecedores à luz do lluminismo, qual seja, a de conhecer a partir do que sou e das minhas referências, nomear, classificar e hierarquizar - conforme nos ensina a forma positivista predominante. 


\section{Lutas feministas, de mulheres e seus rebatimentos na academia}

Por fim e sem pretensões de conclusão em torno de tema tão complexo, elenco alguns limites e o que considero dilemas na construção de aportes acadêmicos em um contexto de acirramento da crise e de caminhos de recrudescimento de imposição autoritária da ordem, criminalização de movimentos sociais insurgentes e de busca por certezas em embate com formas de resistências nas diversidades de existências.

Não é possível a escrita desse artigo sem que consideremos o aprofundamento da crise do capitalismo, com a forte ascensão da extrema direita. Em especial no Brasil, esta vem balizada na militarização, nos discursos e práticas de ódio e extermínio a tudo o que não se conforma como o homem branco possessivo - sobram exemplos e dados crescentes sobre práticas misóginas na sociedade e estimuladas pelo Estado, de aumento de feminicídios ${ }^{14}$ e de políticas de extermínio de populações indígenas, negras e trans.

A universidade, especialmente a pública, não está imune ao controle e ao autoritarismo existentes. Mas, ao mesmo tempo em que pesquisas com temas críticos, que têm por centro "objetos" de estudos que são alvos dos discursos de ódio e da política estatal de aniquilamento deste outro (nas palavras de Achilles Mbembe, da necropolítica, 2016), trazem também suas questões internas sobre as formas de assimilação dos elementos que tratamos aqui nesse trabalho. Não nos caberá muito espaço para o aprofundamento dessas questões, tão relevantes quanto às anteriormente trabalhadas. Mas é importante ressaltar que, ainda que os debates sobre identidade de gênero, questões raciais e de sexo - assim como de leituras fundadas nas contradições entre classe social - encontram nas universidades públicas flancos de resistência de forma bastante diferenciada entre os temas, por vezes, e de forma ainda tímida, conseguem promover integração, no sentido de

${ }^{14}$ O Brasil é o quinto país em feminicídios no mundo, tendo sofrido em 2020 um aumento de mais de $22 \%$ de casos em doze estados entre março e abril de 2020 durante a pandemia de Covid - com o confinamento - se compararmos os dados do mesmo período em 2019 (FBSP, 2020). Na última década, como reflexo da força do racismo estrutural, o extermínio de pessoas negras cresceu em $11 \%$ na contramão da diminuição de $12 \%$ do assassinato de brancos (Atlas da Violência, IPEA/FBSP, 2020). Também carrega a triste marca de ser o país que mais mata pessoas LGBTQI+ no mundo (ANTRA,2019) nos últimos dez anos, bem como denúncias apontam para o incremento do assassinato de ativistas e de indígenas desde 2018, quando da posse do atual presidente, Jair Bolsonaro (sem partido). 
pensar essas distintas marcações nas suas particularidades e importância na leitura sobre a realidade, como é o caso da incorporação do debate metodológico sobre interseccionalidade. O importante é ressaltar que esse saber acadêmico é tensionado pelas lutas sociais concretas e, ainda que com baixa permeabilidade, é possível reconhecer produções e espaços de formação nas universidades públicas brasileiras.

De alguma forma, ainda que incipientemente, no campo da produção de conhecimento acadêmico, movimentos de ruptura com a naturalização das opressões têm sido realizados. Essa naturalização assenta-se sobre uma reificação (e, como parte disso, objetificação) do que é ser mulher ou de quais são as formas que estruturam essa forma social mercantil que se materializa na modernidade.

Esta, por sua vez, se não é boa, em nenhuma instância, para mulher alguma ainda que algumas adquiram ganhos secundários ou se protejam por privilégios próprios aos marcadores específicos, como, por exemplo, as mulheres brancas de classes sociais ou de segmento de classes mais abastadas - impacta de forma estrutural cotidiana e violentamente àquelas que passam ao largo dessa imposição normativa. Talvez um dos legados e aprendizados relevantes dessas mulheres em movimento (CARNEIRO, 2003) tem sido nos tensionar a não nos voltar a constituir consensos ou outras novas definições conceituais universalizadoras e estagnadas sobre existências de mulheres (negras, lésbicas, trans etc). Na linha da argumentação de Fraser (2019), o tensionamento interno aos movimentos feministas por busca de consensos para atender às demandas impostas pelo Estado quanto aos limites do desenho das políticas públicas e de suas respostas, acentuou (e acentua) feridas históricas no que tange às relações sociais entre as classes, raças e mesmo no que se refere às questões identitárias.

Chamamos a atenção, por fim, sobre a necessidade de ouvir, de lidar com a alteridade sem hierarquizá-la e desumanizá-la na outridade, de (re)conhecer movimentos concretos da realidade, revendo e desconstruindo alguns princípios políticos. Nos referimos às amarras raciais, sexuais e sociais (classistas), que impõem o manto da invisibilidade e do silenciamento, especialmente a partir da negação sobre a validação de determinados saberes e de sua desqualificação.

Esse movimento nos auxiliaria a desengavetar pré-definições quanto a gênero, sem necessariamente impor sua fusão na violência do consenso que silencia e oprime. Esses princípios que orientam aquilo que feminismos e movimentos de mulheres (críticos e anticapitalistas) negros, indígenas, decoloniais e 
transfeminismos problematizam a partir da denúncia das invisibilidades e homogeinizações no saber, pode ser entendido como a exposição de novas formas, caminhos e recursos de valorização, resgate e produção de saberes ${ }^{15}$.

São pressupostos importantes que necessitam estar presentes na construção de epistemes e de metodologias de ensino, pesquisa e de sistematização de saberes críticos na academia e no cotidiano das lutas políticas.

\section{Referências}

ADICHIE, Chimamanda Ngozi. O perigo de uma história única. São Paulo: Companhia das Letras, 2019.

ATLAS DA VIOLÊNCIA 2020. IPEA/FBSP, 2020. Disponível em https://www.ipea.gov.br/atlasviolencia/download/24/atlas-da-violencia-2020 Acesso em 23 de dezembro de 2020.

BENEVIDES, Bruna G. e NOGUEIRA, Naider Bonfim Sayonara (Orgs). Dossiê dos assassinatos e da violência contra travestis e transexuais brasileiras em 2019. São Paulo: Expressão Popular, ANTRA, IBTE, 2020. Disponível em https://antrabrasil.files.wordpress.com/2020/01/dossic3aa-dos-assassinatos-e-daviolc3aancia-contra-pessoas-trans-em-2019.pdf Acesso em 22 de dezembro de 2020.

CARNEIRO, Sueli. Mulheres em movimento. Estudos avançados, 17(49), 2003. Disponível em https://www.revistas.usp.br/eav/article/view/9948/11520. Acesso em 19 de dezembro de 2020.

COLLINS, Patricia Hill. Pensamento feminista negro: o poder da autodefinição. In: HOLLANDA, Heloisa Buarque de. (org). Pensamento Feminista - conceitos fundamentais. Rio de Janeiro: Bazar do Tempo, 2019.

COUTINHO, Carlos Nelson. Cultura e sociedade no Brasil: ensaios sobre ideias e formas. Rio de Janeiro: DP\&A, 2000.

DAVIS, Angela. Mulher, raça e classe. São Paulo: Boitempo Editorial. FANON, Frantz. Pele negra, máscaras brancas. Salvador: EDUFBA, 2008.

\footnotetext{
${ }^{15}$ Algumas autoras (es) indicam como uma "nova episteme", mas sempre nos colocamos com cuidado em relação a isso, para que, a título de desconstruir práticas e visibilizar outros enfoques, não o façamos com as mesmas fórmulas.
} 
FEDERICI, Silvia. Feminismo e a política dos comuns. In: HOLLANDA, Heloisa Buarque de. (org). Pensamento Feminista - conceitos fundamentais. Rio de Janeiro: Bazar do Tempo, 2019.

Paulo: Elefante, 2017.

O calibã e a bruxa: mulheres, corpo e acumulação primitiva. São

FÓRUM Brasileiro de Segurança Pública (FBSP). Violência Doméstica durante a Pandemia de Covid-19. Nota técnica, 29 de maio de 2020. Disponível em https://forumseguranca.org.br/wp-content/uploads/2020/06/violencia-domesticacovid-19-ed02-v5.pdf Acesso em 20 de dezembro de 2020.

GONÇALVES, Scheilla Nunes. Mulheres dos escombros: a condição das mulheres periférica em tempos de catástrofes. Rio de Janeiro: Revan, 2019.

GONZALES, Lelia. Racismo e sexismo na cultura brasileira. Revista Ciências Sociais Hoje, Anpocs, 1984, p. 223-244.

LUGONES, María. Colonialidad y genero. Revista Tabula Rasa. Bogotá - Colombia, No.9: $\quad 73-101, \quad$ julio-diciembre 2008 Disponível em http://www.revistatabularasa.org/numero-9/05lugones.pdf. Acesso em 19 de dezembro de 2020.

. Rumo a um feminismo descolonial. Estudos Feministas, Florianópolis, 22(3): 320 , setembro-dezembro/2014. Disponível em http://www.scielo.blr/pdf/ref/v22n3/13.pdf. Acesso em 19 de dezembro de 2020.

MARSHALL, Thomas Humphrey. Cidadania, classe social e status. Rio de Janeiro: Zahar Editora, 1967.

MBEMBE, Achilles. Necropolítica. Arte \& Ensaios, Revista do PPGAV/EBA/UFRJ, n. 32, 2016. Disponível em https://revistas.ufrj.br/index.php/ae/article/view/8993/7169. Acesso em 23 de dezembro de 2020.

MENEGAT, Marildo. A crítica do capitalismo em tempos de catástrofe. O giro dos ponteiros no pulso de um morto e outros ensaios. Rio de Janeiro: Consequência, 2019.

OLIVEIRA, Francisco de. Crítica à razão dualista/O ornitorrinco. São Paulo, Boitempo, 2003.

PEREIRA, Tatiana Dahmer. Sobre resistências, medo e esperança em tempos de colapso. Argumentum, Vitória, v. 11, n. 1, p. 8-21, jan./abr. 2019. Disponível em https://periodicos.ufes.br/argumentum/issue/view/959. Acesso em 22 de janeiro de 2021.

et al. Sobre humanos e destituição de humanidades - da construção do ódio à diferença na modernidade periférica. RAMOS, Adriana et al. (orgs) Desenvolvimento, formação social brasileira e políticas públicas: subsídios 
analíticos para o serviço social, 2019. Editora Navegando, 2019. Disponível em https://www.academia.edu/41998176/Livro_Editora_Navegando_Forma\%C3\%A7\%C 3\%A3o_Social_PPGSSDR.

PINTO, Céli Regina Jardim. Feminismo, história e poder. Rev. Sociol. Polít., Curitiba, v. $18, \quad$ n. 36 , p. 15-23, jun. 2010. Disponível em https://www.scielo.br/pdf/rsocp/v18n36/03.pdf Acesso em 20 de dezembro de 2020.

Perseu Abramo, 2003.

Breve história do feminismo no Brasil. São Paulo: Fundação

SCHOLZ, Roswitha. O valor é homem: teses sobre a socialização pelo valor e a relação entre os sexos. Novos Estudos. CEBRAP, São Paulo, n. 45, julho 1996, p. 15-36.

SEGATO, Rita Laura. Os percursos do gênero na antropologia e para além dela. Série Antropologia. Brasília, $1998 . \quad$ Acessível em http://www.miniweb.com.br/Historia/artigos/i_antiga/pdf/serie236empdf.pdf. Acesso em 19 de dezembro de 2020.

Identidades políticas/Alteridades históricas: uma crítica a las certezas del pluralismo global. La nación y sus otros: raza, etnicidade y diversidad religiosa em tiempos de políticas de la identidad. 1 ${ }^{\underline{a}}$ Ed. Buenos Aires: Prometeo Libros, 2007.

Disponível

La guerra contra las mujeres. Traficante de Suenos, 2016. https://www.traficantes.net/sites/default/files/pdfs/map45_segato_web.pdf. Acesso em 19 de dezembro de 2020.

TELES, Maria Amélia de Almeida. Uma breve história do feminismo. São Paulo: Ed. Brasiliense, 1999.

VIEIRA, Helena e BAGAGLI, Bia Pagliarini. Transfeminismo. In: Heloísa Buarque de Hollanda (org). Explosão feminista: arte, cultura, política e universidade. São Paulo: Companhia das Letras, 2018.

WOOD, Ellen Meiksins. As origens agrárias do Capitalismo. Crítica Marxista, São Paulo, Boitempo, v.1, n.10, 2000. 